\title{
Pengaruh Disiplin dan Motivasi terhadap Kinerja Pegawai pada Badan Pengelola Pajak dan Retribusi Daerah (BPPRD) Kota Jambi
}

\author{
Desita Aliana* \\ BPSDM Provinsi Jambi \\ *Corresponding email: desitaaliana@gmail.com
}

\begin{abstract}
Humane resource management is a process that consists of planning, organizing, leaders andcontrolling activities related to job analysis, job evaluation, procurement, development, compensation, promotion, and termination of employment in order to achieve the stated objectives. The method used in this research is the study of literature's, a study conducted by using literature and writer's that is closely related to the object of study, which is intended to obtain studid. Besides theory and information sourced from the internet. BPPRD is one of the Regional Work Units covered by the Jambi City Government which was formed based on Jambi City Regional Regulation Number 14 of 2016 concerning the Establishment and Composition of Regional XDevices of Jambi City and JambiH Mayor Regulation Number 60 of 2016 concerning Position, Organizational Structure, Tasks, e and Functions and Work Procedures at the Jambi City BPPRD. Based on the results of the regression analysis it was concluded that the regression equation $Y=12559,175+5.284 X 1+7.165 X 2+e$, with $R$ square 0.888 . simultaneously has a rsignificant positive influence between discipline and motivation on the performance of employees with a significant value of 0,000. While quantitatively there is an influence of discipline on employee performance with a significant value of 0.68 and rmotivation towards employee performance with a significant value of 0.003. Because in this study discipline and motivation have a significant effect simultaneously on employee performance. Then it must be more attention and improved again, so that discipline and motivation on employee performance can be better in the future.
\end{abstract}

Keywords: discipline; motivation; employee performance.

\section{PENDAHULUAN}

Badan Pengelola Pajak dan Retribusi Daerah Kota Jambi adalah merupakan Perangkat kerja Daerah dilingkungan Pemerintahan Kota Jambi yang digagas merujuk Peraturan Daerah Kota Jambi Nomor 14 Tahun 2016 tentang Pembentukan dan Susunan Perangkat Daerah Kota Jambi dan Peraturan Walikota Jambi Nomor 60 Tahun 2016 tentang kedudukan dan struktur organisasi, pelaksanaan tugas,fungsi dan aturan kerja pada Badan Pengelola Pajak dan Retribusi Daerah Kota Jambi (BPPRD).

Dalam pembentukan peraturan yang tegas, lugas dan adil yang dilakukan Badan Pengelola Pajak dan Retribusi Daerah Kota Jambi (BPPRD), dapat memberikan dampak positif terhadap kesadaran Para pegawai untuk lebih taat kepada aturan kerjanya sehingga hasil kerja atau kinerjanya dapat meningkat dari tahun ketahun, adapun sasaran Badan Pengelola Pajak dan Retribusi Daerah Kota Jambi (BPPRD) agar dapat tercapai tujuan atau hasil kinerja yang lebih baik maka perlu diterapkan aturan yang mengikat agar dapat memotivasi dan meningkatkan kinerja seluruh pegawai.

Disiplin adalah kesadaran dan prilaku seseorang untuk menaati semua aturan dan norma-norma sosial yang ada yang ada di dalam suatu organisasi perusahaan (Hasibuan, 2014). Dengan disiplin diharapkan pegawai Badan Pengelola Pajak dan Retribusi Daerah (BPPRD) Kota Jambi agar lebih cepat meningkatkan etos kerja, seperti tiba ke kantor tepat pada waktunya, tidak merusak perlengkapan atau alat yang ada di Badan Pengelola Pajak dan Retribusi Daerah (BPPRD) Kota
Jambi, memiliki pertanggung jawaban kerja yang tinggi serta taat kepada peraturan-peraturan yang berlaku di dalam suatu lingkungan kerja yang punya intensitas tinggi.

Sumber daya manusia (SDM) yang berkualitas dapat dilihat melalui kinerja pegawai yang baik dan berprestasi. Kinerja menurut Answar Prabu Mangkunegara (2011) adalah hasil kerja secara kualitas dan jumlah yang dicapai oleh seseorang pegawai/pekerja dalam melaksanakan pekerjaannya sesuai dengan tanggung jawab yang diberikan kepadanya. Kinerja yang bagus dapat dilihat dari tingkat disiplin kerja yang tinggi serta motivasi untuk menunjang kinerja yang semakin baik.

\section{Tinjauan Pustaka Disiplin}

Menurut Hasibuan (2014) arti dari Disiplin adalah "kesadaran dari diri sendiri untuk mematuhi semua peraturan yang berlaku di perusahan organisasi serta norma-norma sosial yang berlaku, sedangkan kesadaran adalah wujud dari sikap seseorang secara sukarela mematuhi semua peraturan dan sadar akan tugas dan tanggung jawabnya dalam bekerja, jadi karyawan akan mematuhi dan mengerjakan semua tugas yang diberikan dengan baik bukan atas paksaan. Kesediaan adalah suatu prilaku, atau tingkah laku dan perbuatan seseorang yang sesuai dengan peraturan organisasi kelompok baik itu tertulis tidak.

\section{Motivasi}


Menurut Hasibuan (2014) menjelaskan bahwa "motivasi adalah suatu perubahan di dalam pribadi seseorang yang ditandai dengan timbulnya afektif dan reaksi untuk mencapai tujuan". Motivasi mengandung 3 (tiga) unsur yang saling berkaitan, yaitu : 1) motivasi dimulai dari adanya perubahan secara besar dalam pribadi, 2) motivasi ditandai dengan timbulnya sikaf (affective aronsal), 3) motivasi ditandai oleh reaksireaksi untuk mencapai tujuan dan target.

\section{Kinerja}

Menurut Hasibuan (2014) Kinerja adalah suatu pencapaian dalam melaksanakan tugas-tugas atas dasar pengetahuan dan kecakapan dalam penyelesaiannya. Berdasarkan paparan diatas kinerja adalah suatu hasil yang dicapai seseorang dalam melaksanakan tugas-tugas yang didasarkan atas pengetahuan dan kecakapan, pengalaman dan kesungguhan serta waktu menurut standar dan kriteria yang telah ditetapkan sebelumnya.

\section{METODE \\ Analisis Deskriptif}

Dalam penelitian ini penulis akan mencoba menganalisa data yang telah diperoleh secara deskriptif kualitatif atau menjabarkan secara menyeluruh. Analisis dilakukan berdasarkan teori yang mempunyai kaitan erat dengan aspek yang diteliti. Menurut Umar (2013) analisis deskriptif kualitatif adalah menyesuiakan situasi sebenarnya dan menggambarkan karakteristik peristiwa yang diteliti serta memberikan kesimpulan secara benar dan menyeluruh berdasarkan metode dan kajian ilmiah dan menggunakan teori-teori yang dipelajari dan konsep yang sesuai dalam permasalahan sebagai acuan untuk berpijak dalam menganalisis sebuah penelitian.

Untuk mencerna permasalahan diatas digunakan skala penelitian dengan menghitung frekuensi nilai skor setiap poin pertanyaan yang diajukan. Seperti yang dikemukakan Umar (2013) bahwa perhitungan skor setiap komponen yang diteliti dengan mengalikan seluruh frekuensi data dengan nilai bobot.

Rumus yang digunakan adalah :

Skor terendah $=$ Bobot terendah $\mathrm{x}$ jumlah sampel

skor tertinggi $=$ Bobot tertinggi $\mathrm{x}$ jumlah sampel

Skor terendah $=1 \times 65$

$$
=65
$$

Skor tertinggi $=5 \times 65$

$$
=325
$$

Sedangkan untuk mencari rentang skala menurut Umar (2013) digunakan rumus sebagai berikut :

$$
\text { Rentang skala }=\frac{n(m-1)}{M}
$$

Dimana :

RS = Rentang Skala

$\mathrm{n}=$ Jumlah Sampel

$\mathrm{m}=$ Jumlah Alternatif Jawaban Item
Rentang Skala $=\frac{65(5-1)}{5}=52$

Skor Kategori

65 - 116 Sangat Tidak Setuju

117 - 181,9 Tidak Setuju

182 - 246,9 Cukup Setuju

247 - 311,9 Setuju

312 - 325 Sangat Setuju

\section{Analisis Verifikatif}

\section{Persamaan Regresi Linier Berganda}

Analisis regresi linier berganda ialah hubungan secara searah antara dua atau lebih variabel independen atau bebas ( $\mathrm{X} 1, \mathrm{X} 2, \ldots . \mathrm{Xn}$ ) dengan variabel dependen terikat (Y). Analisis ini untuk mengetahui arah hubungan antara variabel independen dengan variabel dependen apakah masing-masing variabel independen berhubungan positif atau negatif dan untuk memprediksi nilai dari variabel dependen apabila nilai variabel dependen mengalami peningkatan atau penurunan. Data yang digunakan biasanya berskala interval atau rasio. (Sugiyono, 2010).

$$
\begin{aligned}
& \mathrm{Y}=\mathrm{a}+\mathrm{b}_{1} \mathrm{X}_{1}+\mathrm{b}_{2} \mathrm{X}_{2}+\mathrm{e} \\
& \text { Keterangan : } \\
& \mathrm{Y}=\text { Kinerja. } \\
& \mathrm{a}=\text { Nilai Konstanta } \\
& \mathrm{b}=\text { Koefisien Variabel Independen } \\
& \mathrm{X}_{1}=\text { Disiplin } \\
& \mathrm{X}_{2}=\text { Motivasi } \\
& \mathrm{e}=\text { Error }
\end{aligned}
$$

\section{Koefisien Korelasi}

Koefisien korelasi adalah nilai yang menunjukkan kuat atau tidaknya hubungan linier antar dua variabel (Priyanto, 2013)

Tingkat Keratan Hubungan :

0,000 - 1,999 Sangat Tidak Erat

$0,20-0,399$ Tidak Erat

$0,40-0,599$ Cukup Erat

$0,60-0,799$ Erat

$0,80-0,1000$ Sangat Era

\section{Koefisien Determinasi}

Analisis determinasi digunakan untuk mengetahui pengaruh variabel independen terhadap variabel dependen dalam bentuk persentase. Jika semakin kecil koefisien determinasi, maka semakin terbatas variabel independen menjelaskan variabel dependen (Priyanto, 2013). Besarnya koefisien determinasi dari 0 sampai dengan 1. Semakin mendekati 0 besarnya koefisien determinasi suatu persamaan regresi, maka semakin kecil pula pengaruh semua variabel independen terhadap nilai variabel dependen. Sebaliknya, semakin mendekati 1 besarnya koefisien determinasi suatu persamaan regresi, maka semakin besar pula pengaruh semua variabel independen terhadap variabel dependen 
Desita Aliana, Pengaruh Disiplin dan Motivasi terhadap Kinerja Pegawai pada Badan Pengelola Pajak dan Retribusi Daerah (BPPRD) Kota Jambi

(Algifari, 2009). Menurut Priyanto (2013), bahwa untuk regresi dengan lebih dari dua variabel digunakan Adjusted R2 sebagai koefisien determinasi. Adjusted R Square adalah nilai $\mathrm{R} S$ square yang telah disesuaikan.

\section{HASIL DAN PEMBAHASAN Analisis Deskriptif}

1. Analisis Disiplin Pegawai Pada Badan Pengelola Pajak Dan Retribusi Daerah (BPPRD) Kota Jambi

a. Teladanan Pimpinan

Berdasarkan hasil jawaban dari para responden terhadap penilaian keteladanan pimpinan ialah sbb:

Tabel 1. Deskriptif Indikator Teladanan Pimpinan

\begin{tabular}{|c|c|c|c|c|c|c|c|c|}
\hline \multirow{2}{*}{ Pernyataan } & STS & TS & CS & $\mathbf{S}$ & SS & \multirow{2}{*}{ Jumlah } & \multirow{2}{*}{$\begin{array}{c}\text { Jumlah } \\
\text { Skor }\end{array}$} & \multirow{2}{*}{ Kriteria } \\
\hline & 1 & 2 & 3 & 4 & 5 & & & \\
\hline $\begin{array}{l}\text { Konsistensi pimpinan dapat meningkatkan disiplin } \\
\text { karyawan }\end{array}$ & 0 & 0 & 7 & 20 & 38 & 65 & & Setuju \\
\hline & 0 & 0 & 21 & 80 & 190 & & 291 & \\
\hline Kedisiplinan pimpinan menjadi teladan karyawan & 0 & 0 & 5 & 10 & 50 & 65 & & Setuju \\
\hline & 0 & 0 & 15 & 40 & 250 & & 305 & \\
\hline Jumlah & & & & & & & 596 & \\
\hline Rata-rata & & & & & & & 298 & Setuju \\
\hline
\end{tabular}

Sumber: Data Primer (diolah)

Berdasarkan tabel 1 dapat diketahui bahwa secara keseluruhan rata-rata pegawai (BPPRD) Kota Jambi menilai keteladanan pimpinan tersebut berada pada skor 298 artinya dapat dikategorikan setuju melihat rentang skala yang dihasilkan berkisar pada angka 247 - 311,9.

\section{b. Waskat (Pengawasan Melekat)}

Berdasarkan hasil jawaban responden terhadap kuesioner waskat (pengawasan melekat) memiliki indikator sbb:

Tabel 2. Deskriptif Indikator Waskat (Pengawasan Melekat)

\begin{tabular}{|c|c|c|c|c|c|c|c|c|}
\hline \multirow{2}{*}{ Pernyataan } & STS & TS & CS & $\mathbf{S}$ & SS & \multirow[b]{2}{*}{ Jumlah } & \multirow{2}{*}{$\begin{array}{c}\text { Jumlah } \\
\text { Skor }\end{array}$} & \multirow{2}{*}{ Kriteria } \\
\hline & 1 & 2 & 3 & 4 & 5 & & & \\
\hline \multirow[t]{2}{*}{ Sistem pengawasan yang diterapkan pimpinan selama ini } & 2 & 1 & 14 & 22 & 26 & 65 & & Setuju \\
\hline & 2 & 2 & 42 & 88 & 130 & & 264 & \\
\hline \multirow[t]{2}{*}{ Tindaklanjut pengawasan yang dilakukan pimpinan } & 2 & 4 & 10 & 15 & 34 & 65 & & Setuju \\
\hline & 2 & 8 & 30 & 60 & 170 & & 270 & \\
\hline \multicolumn{7}{|l|}{ Jumlah } & 534 & \\
\hline \multicolumn{7}{|l|}{ Rata-rata } & 267 & Setuju \\
\hline
\end{tabular}

Sumber : Data Primer (diolah)

Berdasarkan tabel 2 di atas dijelaskan .bahwa secara keseluruhan rata-rata pegawai (BPPRD) Kota Jambi memberikan penilaian. waskat (pengawasan melekat) tersebut pada skor angka 267 maksudnya bisa dikategorikan setuju sebab berada pada rentang skala angka $247-311,9$.

\section{c. Sanksi Hukuman}

Berdasarkan hasil jawaban responden terhadap sanksi hukuman atau vanismen adalah sebagai berikut:

Tabel 3. Deskriptif Indikator Sanksi Hukuman

\begin{tabular}{|c|c|c|c|c|c|c|c|c|}
\hline \multirow{2}{*}{ Pernyataan } & STS & TS & CS & S & SS & \multirow{2}{*}{ Jumlah } & $\begin{array}{c}\text { Jumlah } \\
\text { Skor }\end{array}$ & Kriteria \\
\cline { 2 - 11 } & $\mathbf{1}$ & $\mathbf{2}$ & $\mathbf{3}$ & $\mathbf{4}$ & $\mathbf{5}$ & & Setuju \\
\hline Diberi teguran bagi pegawai yang melanggar peraturan & 2 & 4 & 8 & 23 & 28 & 65 & & \\
\hline & 2 & 8 & 24 & 92 & 140 & & 266 & \\
\hline Surat peringatan bagi pegawai yang tidak disiplin & 3 & 5 & 5 & 25 & 27 & 65 & & Setuju \\
\hline & 3 & 10 & 15 & 100 & 135 & & 263 & \\
\hline Jumlah & \multicolumn{9}{|l|}{} & & $\mathbf{5 2 9}$ & \\
\hline Rata-rata \\
\hline
\end{tabular}

Sumber : Data Primer (diolah)

Berdasarkan tabel 3. di atas diketahui bahwa secara keseluruhan rata-rata pegawai Badan
Pengelola Pajak Dan Retribusi Daerah (BPPRD) Kota Jambi menilai sanksi hukuman berada pada 
Desita Aliana, Pengaruh Disiplin dan Motivasi terhadap Kinerja Pegawai pada Badan Pengelola Pajak dan Retribusi Daerah (BPPRD) Kota Jambi

rentang skala skor 264,5 maksudnya para pegawai setuju karena berada pada rentang skala 247 - 311,9.

\section{d. Ketegasan Pimpinan}

Berdasarkan hasil jawaban responden terhadap kuesioner mengenai ketegasan pimpinan ialah sbb :

Tabel 4. Deskriptif Indikator Ketegasan Pimpinan

\begin{tabular}{|c|c|c|c|c|c|c|c|c|}
\hline \multirow{2}{*}{ Pernyataan } & STS & TS & CS & $\mathbf{S}$ & SS & \multirow{2}{*}{ Jumlah } & \multirow{2}{*}{$\begin{array}{c}\text { Jumlah } \\
\text { Skor }\end{array}$} & \multirow{2}{*}{ Kriteria } \\
\hline & 1 & 2 & 3 & 4 & 5 & & & \\
\hline \multirow{2}{*}{$\begin{array}{l}\text { Ketegasan pimpinan dalam menerapkan sanksi } \\
\text { hukuman ditempat kerja selama ini }\end{array}$} & 3 & 3 & 2 & 21 & 36 & 65 & & Setuju \\
\hline & 3 & 6 & 6 & 84 & 180 & & 279 & \\
\hline \multirow[t]{2}{*}{$\begin{array}{l}\text { Ketegasan pimpinan menghukum pegawai yang } \\
\text { indisipliner }\end{array}$} & 5 & 3 & 6 & 22 & 29 & 65 & & Setuju \\
\hline & 5 & 6 & 18 & 88 & 145 & & 262 & \\
\hline \multicolumn{7}{|c|}{ Jumlah } & 541 & \\
\hline \multicolumn{7}{|c|}{ Rata-rata } & 270,5 & Setuju \\
\hline
\end{tabular}

Sumber : Data Primer (diolah)

Berdasarkan tabel 4.4 di atas diketahui bahwa secara keseluruhan rata-rata pegawai Badan Pengelola Pajak Dan Retribusi Daerah (BPPRD) Kota Jambi menilai ketegasan pimpinan tersebut berada pada skor 270,5 artinya dapat dikategorikan setuju karena berada pada rentang skala 247 - 311,9.

e. Hubungan Kemanusian

Adapun hasil jawaban responden terhadap hubungan kemanusian adalah sebagai berikut :

Tabel 5. Deskriptif Indikator Hubungan Kemanusian

\begin{tabular}{|c|c|c|c|c|c|c|c|c|}
\hline \multirow{2}{*}{ Pernyataan } & STS & TS & CS & $\mathbf{S}$ & SS & \multirow{2}{*}{ Jumlah } & \multirow{2}{*}{$\begin{array}{c}\text { Jumlah } \\
\text { Skor }\end{array}$} & \multirow{2}{*}{ Kriteria } \\
\hline & 1 & 2 & 3 & 4 & 5 & & & \\
\hline \multirow[t]{2}{*}{$\begin{array}{l}\text { Pegawai memiliki hubungan komunikasi yang baik } \\
\text { dengan rekan kerja }\end{array}$} & 0 & 0 & 5 & 25 & 35 & 65 & & Setuju \\
\hline & 0 & 0 & 15 & 100 & 175 & & 290 & \\
\hline \multirow[t]{2}{*}{$\begin{array}{l}\text { Pimpinan dan pegawai mempunyai kerja sama yang } \\
\text { baik }\end{array}$} & 0 & 0 & 0 & 27 & 38 & 65 & & Setuju \\
\hline & 0 & 0 & 0 & 108 & 190 & & 298 & \\
\hline \multicolumn{7}{|c|}{ Jumlah } & 588 & \\
\hline \multicolumn{7}{|c|}{ Rata-rata } & 294 & Setuju \\
\hline
\end{tabular}

Sumber : Data Primer (diolah)

Berdasarkan tabel 5 di atas diketahui bahwa secara keseluruhan rata-rata pegawai Badan Pengelola Pajak Dan Retribusi Daerah (BPPRD) Kota Jambi menilai hubungan kemanusian tersebut berada pada skor 294 artinya dapat dikategorikan setuju karena berada pada rentang skala 247 - 311,9.
2. Analisis Motivasi Pegawai Pada Badan Pengelola Pajak Dan Retribusi Daerah (BPPRD) Kota Jambi

a. Daya Pendorong

Adapun hasil jawaban responden terhadap daya pendorong adalah sebagai berikut :

Tabel 6. Deskriptif Indikator Daya Pendorong

\begin{tabular}{|c|c|c|c|c|c|c|c|c|}
\hline Pernyataan & STS & TS & CS & S & SS & Jumlah & $\begin{array}{c}\text { Jumlah } \\
\text { Skor }\end{array}$ & Kriteria \\
\hline \multirow{3}{*}{$\begin{array}{l}\text { Jumlah pegawai dapat membuat bapak/ibu termotivasi } \\
\text { dalam menyusun pekerjaan kantor }\end{array}$} & 1 & 2 & 3 & 25 & & & & \\
\hline & 0 & 0 & 5 & 25 & 35 & 65 & & Setuju \\
\hline & 0 & 0 & 15 & 100 & 175 & & 290 & \\
\hline \multirow[t]{2}{*}{$\begin{array}{l}\text { Insentif dapat memberikan dorongan untuk bekerja } \\
\text { lebih baik }\end{array}$} & 0 & 0 & 0 & 27 & 38 & 65 & & Setuju \\
\hline & 0 & 0 & 0 & 108 & 190 & & 298 & \\
\hline \multicolumn{7}{|l|}{ Jumlah } & 588 & \\
\hline \multicolumn{7}{|l|}{ Rata-rata } & 294 & Setuju \\
\hline
\end{tabular}

Sumber : Data Primer (diolah)

Berdasarkan tabel 6 di atas diketahui bahwa secara keseluruhan rata-rata pegawai Badan
Pengelola Pajak Dan Retribusi Daerah (BPPRD) Kota Jambi menilai daya pendorong tersebut berada 
Desita Aliana, Pengaruh Disiplin dan Motivasi terhadap Kinerja Pegawai pada Badan Pengelola Pajak dan Retribusi Daerah (BPPRD) Kota Jambi

pada skor 294 artinya dapat dikategorikan setuju karena berada pada rentang skala 247 - 311,9.

\section{b. Kemauan}

Adapun hasil jawaban responden terhadap kemauan adalah sebagai berikut :

Tabel 7. Deskriptif Indikator Kemauan

\begin{tabular}{|c|c|c|c|c|c|c|c|c|}
\hline \multirow{2}{*}{ Pernyataan } & STS & TS & $\mathbf{C S}$ & $\mathbf{S}$ & SS & \multirow[b]{2}{*}{ Jumlah } & \multirow{2}{*}{$\begin{array}{l}\text { Jumlah } \\
\text { Skor }\end{array}$} & \multirow[b]{2}{*}{ Kriteria } \\
\hline & 1 & 2 & 3 & 4 & 5 & & & \\
\hline \multirow[t]{2}{*}{$\begin{array}{l}\text { Bapak/ibu memiliki kemauan untuk lebih } \\
\text { meningkatkan absensi kehadiran }\end{array}$} & 0 & 0 & 0 & 27 & 38 & 65 & & Setuju \\
\hline & 0 & 0 & 0 & 108 & 190 & & 298 & \\
\hline \multirow[t]{2}{*}{$\begin{array}{l}\text { Adanya kemauan untuk belajar dan tidak pernah } \\
\text { merasa puas dengan apa yang diraih }\end{array}$} & 0 & 0 & 0 & 15 & 50 & 65 & & Setuju \\
\hline & 0 & 0 & 0 & 60 & 250 & & 310 & \\
\hline \multicolumn{7}{|c|}{ Jumlah } & 617 & \\
\hline \multicolumn{7}{|c|}{ Rata-rata } & 308,5 & Setuju \\
\hline
\end{tabular}

Sumber : Data Primer (diolah)

Berdasarkan tabel 7 di atas diketahui bahwa secara keseluruhan rata-rata pegawai Badan Pengelola Pajak Dan Retribusi Daerah (BPPRD) Kota Jambi menilai kemauan tersebut berada pada skor 308,5 artinya dapat dikategorikan setuju karena berada pada rentang skala 247 - 311,9.

c. Keterampilan

Adapun hasil jawaban responden terhadap keterampilan adalah sebagai berikut:

Tabel 8. Deskriptif Indikator Keterampilan

\begin{tabular}{|c|c|c|c|c|c|c|c|c|}
\hline \multirow{2}{*}{ Pernyataan } & STS & TS & $\mathbf{C S}$ & $\mathbf{S}$ & SS & \multirow{2}{*}{ Jumlah } & \multirow{2}{*}{$\begin{array}{c}\text { Jumlah } \\
\text { Skor }\end{array}$} & \multirow{2}{*}{ Kriteria } \\
\hline & 1 & 2 & 3 & 4 & 5 & & & \\
\hline \multirow[t]{2}{*}{$\begin{array}{l}\text { Mau belajar tentang hal yang baru dan menerima } \\
\text { masukan serta saran dari yang berpengalaman }\end{array}$} & 2 & 1 & 14 & 22 & 26 & 65 & & Setuju \\
\hline & 2 & 2 & 42 & 88 & 130 & & 264 & \\
\hline \multirow[t]{2}{*}{ Pegawai mempunyai keterampilan dalam pekerjaan } & 2 & 4 & 10 & 15 & 34 & 65 & & Setuju \\
\hline & 2 & 8 & 30 & 60 & 170 & & 270 & \\
\hline \multicolumn{7}{|c|}{ Jumlah } & 534 & \\
\hline \multicolumn{7}{|c|}{ Rata-rata } & 267 & Setuju \\
\hline
\end{tabular}

Sumber : Data Primer (diolah)

Berdasarkan tabel 8 di atas diketahui bahwa secara keseluruhan rata-rata pegawai Badan Pengelola Pajak Dan Retribusi Daerah (BPPRD) Kota Jambi menilai keterampilan tersebut berada pada skor 267 artinya dapat dikategorikan setuju karena berada pada rentang skala 247 - 311,9.

\section{d. Tanggung Jawab}

Adapun hasil jawaban responden terhadap tanggung jawab adalah sebagai berikut :

Tabel 9. Deskriptif Indikator Tanggung Jawab

\begin{tabular}{|c|c|c|c|c|c|c|c|c|}
\hline \multirow[b]{2}{*}{ Pernyataan } & & & & & & \multirow[b]{2}{*}{ Jumlah } & \multirow[b]{2}{*}{$\begin{array}{c}\text { Jumlah } \\
\text { Skor }\end{array}$} & \multirow[b]{2}{*}{ Kriteria } \\
\hline & $\begin{array}{c}\text { STS } \\
1\end{array}$ & \begin{tabular}{|c|} 
TS \\
2
\end{tabular} & \begin{tabular}{|c|} 
CS \\
3
\end{tabular} & $\begin{array}{l}S \\
4\end{array}$ & $\begin{array}{c}\text { SS } \\
5\end{array}$ & & & \\
\hline \multirow[t]{2}{*}{$\begin{array}{l}\text { Harus adanya ketelitian pegawai dalam mengerjakan } \\
\text { suatu pekerjaan }\end{array}$} & 2 & 4 & 8 & 23 & 28 & 65 & & Setuju \\
\hline & 2 & 8 & 24 & 92 & 140 & & 266 & \\
\hline \multirow[t]{2}{*}{$\begin{array}{l}\text { Kemauan untuk lebih berkomitmen untuk bisa } \\
\text { memberikan yang terbaik kepada perusahaan }\end{array}$} & 3 & 5 & 5 & 25 & 27 & 65 & & Setuju \\
\hline & 3 & 10 & 15 & 100 & 135 & & 263 & \\
\hline \multicolumn{7}{|c|}{ Jumlah } & 529 & \\
\hline \multicolumn{7}{|c|}{ Rata-rata } & 264,5 & Setuju \\
\hline
\end{tabular}

Sumber : Data Primer (diolah)

Berdasarkan tabel 9 di atas diketahui bahwa secara keseluruhan rata-rata pegawai Badan Pengelola Pajak Dan Retribusi Daerah (BPPRD) Kota Jambi menilai tanggung jawab tersebut berada pada skor 264,5 artinya dapat dikategorikan setuju karena berada pada rentang skala 247 - 311,9.

e. Kewajiban

Adapun hasil jawaban responden terhadap kewajiban adalah sebagai berikut : 
Desita Aliana, Pengaruh Disiplin dan Motivasi terhadap Kinerja Pegawai pada Badan Pengelola Pajak dan Retribusi Daerah (BPPRD) Kota Jambi

Tabel 10. Deskriptif Indikator Kewajiban

\begin{tabular}{|c|c|c|c|c|c|c|c|c|}
\hline \multirow{2}{*}{ Pernyataan } & STS & TS & $\mathrm{CS}$ & $\mathbf{S}$ & SS & \multirow{2}{*}{ Jumlah } & \multirow{2}{*}{$\begin{array}{c}\text { Jumlah } \\
\text { Skor }\end{array}$} & \multirow{2}{*}{ Kriteria } \\
\hline & 1 & 2 & 3 & 4 & 5 & & & \\
\hline \multirow[t]{2}{*}{$\begin{array}{l}\text { Pegawai wajib mematuhi peraturan sesuai yang diberikan } \\
\text { oleh pimpinan }\end{array}$} & 3 & 3 & 2 & 21 & 36 & 65 & & Setuju \\
\hline & 3 & 6 & 6 & 84 & 180 & & 279 & \\
\hline \multirow[t]{2}{*}{$\begin{array}{l}\text { Pegawai wajib bertanggungjawab dalam pekerjaan yang } \\
\text { telah diberikan oleh pimpinan }\end{array}$} & 5 & 3 & 6 & 22 & 29 & 65 & & Setuju \\
\hline & 5 & 6 & 18 & 88 & 145 & & 262 & \\
\hline \multicolumn{7}{|l|}{ Jumlah } & 541 & \\
\hline \multicolumn{7}{|l|}{ Rata-rata } & 270,5 & Setuju \\
\hline
\end{tabular}

Sumber : Data Primer (diolah)

Berdasarkan tabel 10 di atas diketahui bahwa secara keseluruhan rata-rata pegawai Badan Pengelola Pajak Dan Retribusi Daerah (BPPRD) Kota Jambi menilai kewajiban tersebut berada pada skor 270,5 artinya dapat dikategorikan setuju karena berada pada rentang skala $247-311,9$.
3. Analisis Kinerja Pegawai Pada Badan Pengelola Pajak Dan Retribusi Daerah (BPPRD) Kota Jambi

a. Prestasi Kerja

Adapun hasil jawaban responden terhadap prestasi kerja adalah sebagai berikut :

Tabel 11. Deskriptif Indikator Prestasi Kerja

\begin{tabular}{|c|c|c|c|c|c|c|c|c|}
\hline \multirow[t]{2}{*}{ Pernyataan } & STS & TS & CS & S & SS & \multirow[t]{2}{*}{ Jumlah } & \multirow[t]{2}{*}{$\begin{array}{c}\text { Jumlah } \\
\text { Skor }\end{array}$} & Kriteria \\
\hline & & 2 & 3 & 4 & & & & \\
\hline \multirow[t]{2}{*}{$\begin{array}{l}\text { Adanya kemauan untuk belajar dan tidak pernah } \\
\text { merasa puas dengan apa yang diraih.mj }\end{array}$} & 0 & 0 & 5 & 25 & 35 & 65 & & Setuju \\
\hline & 0 & 0 & 15 & 100 & 175 & & 290 & \\
\hline \multirow[t]{2}{*}{$\begin{array}{l}\text { Mau belajar tentang hal yang baru dan menerima } \\
\text { masukan serta saran dari yang berpengalaman }\end{array}$} & 0 & 0 & 0 & 27 & 38 & 65 & & Setuju \\
\hline & 0 & 0 & 0 & 108 & 190 & & 298 & \\
\hline \multicolumn{7}{|c|}{ Jumlah } & 588 & \\
\hline \multicolumn{7}{|c|}{ Rata-rata } & 294 & Setuju \\
\hline
\end{tabular}

Sumber : Data Primer (diolah)

Berdasarkan.tabel 11 di atas diketahui, bahwa secara keseluruhan; rata-rata pegawai. Badan Pengelola Pajak,Dan Retribusi Daerah (BPPRD) Kota Jambi menilai prestasi kerja, tersebut berada pada skor. 294 artinya dapat dikategorikan; setuju karena berada pada rentang skala 247 - 311,9.

\section{b. Disiplin Kerja}

Adapun hasil jawaban responden terhadap disiplin kerja adalah sebagai berikut :

Tabel 12. Deskriptif Indikator Disiplin Kerja

\begin{tabular}{|l|c|c|c|c|c|c|c|c|c|}
\hline \multicolumn{1}{|c|}{ Tabel 12. Deskriptif Indikator Disiplin Kerja } \\
\cline { 2 - 13 } & $\mathbf{1}$ & $\mathbf{2}$ & $\mathbf{3}$ & $\mathbf{4}$ & $\mathbf{5}$ & Jumlah & $\begin{array}{c}\text { Jumlah } \\
\text { Skor }\end{array}$ & Kriteria \\
\hline $\begin{array}{l}\text { Ketepatan waktu lebih diperketat agar pegawai lebih } \\
\text { disiplin }\end{array}$ & 0 & 0 & 2 & 10 & 53 & 65 & & \multirow{2}{*}{ Setuju } \\
\hline $\begin{array}{l}\text { Adanya ketentuan sanksi-sanksi yang telah ditetapkan } \\
\text { dari perusahaan }\end{array}$ & 0 & 0 & 6 & 40 & 265 & & 311 & \\
\hline & 0 & 0 & 21 & 80 & 190 & & 291 & Setuju \\
\hline \multicolumn{7}{|c|}{ Jumlah } \\
\hline
\end{tabular}

Sumber : Data Primer (diolah)

Berdasarkan tabel 12 di atas diketahui bahwa secara keseluruhan rata-rata pegawai Badan Pengelola Pajak Dan Retribusi Daerah (BPPRD) Kota Jambi menilai disiplin kerja tersebut berada pada skor 301 artinya dapat dikategorikan setuju karena berada pada rentang skala 247 - 311,9.

c. Efektivitas Dan Efisiensi Kerja

Adapun hasil jawaban responden terhadap efektivitas dan efisiensi kerja adalah sebagai berikut : 
Desita Aliana, Pengaruh Disiplin dan Motivasi terhadap Kinerja Pegawai pada Badan Pengelola Pajak dan Retribusi Daerah (BPPRD) Kota Jambi

Tabel 13. Deskriptif Indikator Efektivitas Dan Efisiensi Kerja

\begin{tabular}{|c|c|c|c|c|c|c|c|c|}
\hline \multirow{2}{*}{ Pernyataan } & STS & TS & CS & $S$ & SS & \multirow{2}{*}{ Jumlah } & \multirow{2}{*}{$\begin{array}{c}\text { Jumlah } \\
\text { Skor }\end{array}$} & \multirow{2}{*}{ Kriteria } \\
\hline & 1 & 2 & 3 & 4 & 5 & & & \\
\hline \multirow[t]{2}{*}{$\begin{array}{l}\text { Adanya kemauan mencapai tujuan yang telah } \\
\text { ditetapkan }\end{array}$} & 2 & 4 & 10 & 15 & 34 & 65 & & Setuju \\
\hline & 2 & 8 & 30 & 60 & 170 & & 270 & \\
\hline \multirow[t]{2}{*}{$\begin{array}{l}\text { Adanya standarisasi dalam penerapan kinerja } \\
\text { pegawai }\end{array}$} & 2 & 1 & 14 & 22 & 26 & 65 & & Setuju \\
\hline & 2 & 1 & 42 & 88 & 130 & & 264 & \\
\hline \multicolumn{7}{|c|}{ Jumlah } & 534 & $S^{\prime}$ \\
\hline
\end{tabular}

Sumber : Data Primer (diolah)

Berdasarkan tabel 13 di atas diketahui bahwa secara keseluruhan rata-rata pegawai Badan Pengelola Pajak Dan Retribusi Daerah (BPPRD) Kota Jambi menilai efektivitas dan efisiensi kerja tersebut berada pada skor 267 artinya dapat dikategorikan setuju karena berada pada rentang skala $247-311,9$.

d. Tanggung Jawab

Adapun hasil jawaban responden terhadap tanggung jawab adalah sebagai berikut :

Tabel 14. Deskriptif Indikator Tanggung Jawab

\begin{tabular}{|c|c|c|c|c|c|c|c|c|}
\hline \multirow{2}{*}{ Pernyataan } & STS & TS & CS & $\mathbf{S}$ & SS & \multirow{2}{*}{ Jumlah } & \multirow{2}{*}{$\begin{array}{l}\text { Jumlah } \\
\text { Skor }\end{array}$} & \multirow{2}{*}{ Kriteria } \\
\hline & 1 & 2 & $\mathbf{3}$ & 4 & 5 & & & \\
\hline \multirow[t]{2}{*}{$\begin{array}{l}\text { Kemauan untuk lebih berkomitmen untuk bisa } \\
\text { memberikan yang terbaik kepada perusahaan }\end{array}$} & 0 & 0 & 0 & 27 & 38 & 65 & & Setuju \\
\hline & 0 & 0 & 0 & 108 & 190 & & 298 & \\
\hline \multirow[t]{2}{*}{$\begin{array}{l}\text { Harus adanya ketelitian pegawai dalam mengerjakan } \\
\text { suatu pekerjaan }\end{array}$} & 0 & 0 & 5 & 25 & 35 & 65 & & Setuju \\
\hline & 0 & 0 & 15 & 100 & 175 & & 290 & \\
\hline \multicolumn{7}{|c|}{ Jumlah } & 588 & \\
\hline \multicolumn{7}{|c|}{ Rata-rata } & 294 & Setuju \\
\hline
\end{tabular}

Sumber : Data Primer (diolah)

Berdasarkan tabel 14 di atas diketahui bahwa secara keseluruhan rata-rata pegawai Badan Pengelola Pajak Dan Retribusi Daerah (BPPRD) Kota Jambi menilai tanggung jawab tersebut berada pada skor 294 artinya dapat dikategorikan setuju karena berada pada rentang skala 247 - 311,9.

e. Hubungan Antar Sesama

Adapun hasil jawaban responden terhadap hubungan antar sesama adalah sebagai berikut :

Tabel 15. Deskriptif Indikator Hubungan Antar Sesama

\begin{tabular}{|c|c|c|c|c|c|c|c|c|}
\hline \multirow{2}{*}{ Pernyataan } & STS & TS & CS & $\mathbf{S}$ & SS & \multirow{2}{*}{ Jumlah } & \multirow{2}{*}{$\begin{array}{l}\text { Jumlah } \\
\text { Skor }\end{array}$} & \multirow{2}{*}{ Kriteria } \\
\hline & 1 & 2 & 3 & 4 & 5 & & & \\
\hline \multirow{2}{*}{$\begin{array}{l}\text { Meningkatkan rasa tenggang rasa antar pegawai agar } \\
\text { rasa saling menjaga satu sama lain terjalin }\end{array}$} & 0 & 0 & 7 & 20 & 38 & 65 & & Setuju \\
\hline & 0 & 0 & 21 & 80 & 190 & & 291 & \\
\hline \multirow[t]{2}{*}{$\begin{array}{l}\text { Menjaga sikap, tutur kata dan rasa saling memiliki } \\
\text { dengan tujuan mempererat tali persaudaraan }\end{array}$} & 0 & 0 & 5 & 10 & 50 & 65 & & Setuju \\
\hline & 0 & 0 & 15 & 40 & 250 & & 305 & \\
\hline \multicolumn{7}{|c|}{ Jumlah } & 596 & \\
\hline \multicolumn{7}{|c|}{ Rata-rata } & 298 & Setuju \\
\hline
\end{tabular}

Sumber : Data Primer (diolah)

Berdasarkan:tabel 15 di atas diketahuik bahwa secara keseluruhan rata-rataP pegawai Badan Pengelola Pajak Dan Retribusi Daerah (BPPRD) Kota Jambi menilai hubungan antar sesama tersebut berada pada skor 298 artinyaJdapat dikategorikan setuju karena berada' pada rentang skala 247-311,9.

\section{Persamaan Regresi Linier Berganda}

Hasil estimasi pengaruh disiplin (X1) dan motivasi (X2) terhadap kinerja (Y) dengan menggunakan komputer program SPSS versi 20 diperoleh perhitungan sebagai berikut : 
Desita Aliana, Pengaruh Disiplin dan Motivasi terhadap Kinerja Pegawai pada Badan Pengelola Pajak dan Retribusi Daerah (BPPRD) Kota Jambi

Tabel 16. Hasil Uji Regresi Linier Sederhana

Coefficients $^{\mathrm{a}}$

\begin{tabular}{|c|c|c|c|}
\hline \multirow[t]{2}{*}{ Model } & \multicolumn{2}{|c|}{$\begin{array}{c}\text { Unstandardized } \\
\text { Coefficients }\end{array}$} & $\begin{array}{l}\text { Standardized } \\
\text { Coefficients }\end{array}$ \\
\hline & B & $\begin{array}{l}\text { Std. } \\
\text { Error }\end{array}$ & Beta \\
\hline (Constant) & 12559,175 & 4457,712 & \\
\hline DISIPLIN & 5,284 & 2,503 &,- 600 \\
\hline MOTIVASI & 7,165 & 1,717 & 2,192 \\
\hline
\end{tabular}

a. Dependent Variable: KINERJA PEGAWAI

Berdasarkan; tabel 4.9 diatas hasil uji regresi linier sederhana dapat diperoleh koefisien untuk variabel bebas $\mathrm{X} 1=5.284$ dan $\mathrm{X} 2=7.165$, konstanta, sebesar 12559,175 sehingga model persamaan regresi yang diperoleh :

$\mathrm{Y}=\mathrm{a}+\mathrm{b}_{1} \mathrm{X}_{1}+\mathrm{b}_{2} \mathrm{X}_{2}+\mathrm{e}$

$\mathrm{Y}=12559,175+5.284 \mathrm{X}_{1}+7.165 \mathrm{X}_{2}+\mathrm{e}$

\section{Koefisien Korelasi Dan Determinasi}

Tabel 17. Hasil Uji Korelasi Model Summary ${ }^{b}$

\begin{tabular}{|l|c|r|r|}
\hline Model & R & \multicolumn{1}{|c|}{ R Square } & Adjusted R Square \\
\hline 1 &, $942^{\mathrm{a}}$ &, 888 &, 21092 \\
\hline
\end{tabular}

a. Predictors: (Constant), DISIPLIN, MOTIVASI

b. Dependent Variable: KINERJA PEGAWAI

Berdasarkan tabel 17 diatas diperoleh nilai koefisien korelasi (R) variabel independen sebesar 0,942. Nilai ini menunjukkan bahwa hubungan disiplin dan motivasi terhadap kinerja pegawai pada Badan Pengelola Pajak Dan Retribusi Daerah (BPPRD) Kota Jambi Tahun 2013 - 2017 sangat erat yaitu 0,942.

Sedangkan nilai koefisien determinasi (R2) sebesar 0.888 hal itu berarti bahwa variasi perubahan $\mathrm{Y}$ dipengaruhi oleh perubahan X1 dan X2 sebesar 88,8\%. Jadi besarnya pengaruh disiplin dan motivasi terhadap kinerja pegawai adalah sebesar $88,8 \%$ sedangkan sisanya sebesar $11,2 \%$ dipengaruhi oleh faktor lain diluar penelitian ini.

\section{SIMPULAN}

1. Disiplin dan motivasi secara bersama-sama (Simultan) berpengaruh terhadap kinerja pegawai.

2. Secara sendiri-sendiri (Parsial) terdapat pengaruh disiplin dan motivasi terhadap kinerja pegawai.

3. Terdapat pengaruh yang signifikan antara disiplin dan motivasi terhadap kinerja pegawai pada Badan Pengelola Pajak Dan Retribusi Daerah (BPPRD) Kota Jambi Tahun 2013 - 2017. Ini ditunjukkan dari hasil perhitungan nilai koefisien korelasi adalah 0,942 yang artinya menunjukkan ada hubungan yang sangat erat antara ketiga variabel.

\section{DAFTAR PUSTAKA}

Algifari. 2009. Statistik Induktif. Edisi Kedua. Yogyakarta.

Answar Prabu Mangkunegara. 2011. Manajemen Sumber Daya Manusia Perusahaan. Remaja Rosdakarya. Bandung.

Hasibuan, S.P. 2014. Manajemen Sumber Daya Manusia. Edisi Revisi Pt Bumi Aksara. Jakarta.

Priyanto, Duwi. 2013. Analisis Korelasi, Regresi dan Multivariate dengan SPSS. Yogyakarta: Gava Media

Sugiyono. 2010. Metode Penelitian Pendidikan Pendekatan Kuantitatif, kualitatif, dan $R \& D$. Bandung: Alfabeta

Umar, Husen. (2013). Metode Penelitian untuk Skripsi dan Tesis. Jakarta: Rajawali. 